\title{
PROTEOMIC ANALYSIS OF CERVICAL-VAGINAL FLUID: IDENTIFICATION OF NOVEL BIOMARKERS FOR DETECTION OF INTRA-AMNIOTIC INFECTION
}

\author{
Michael G. Gravett ${ }^{1,2}$, Archana Thomas ${ }^{3}$, Kimberly A. Schneider ${ }^{3}$, Ashok P. Reddy ${ }^{3}$, \\ Surendra Dasari ${ }^{4}$, Thomas Jacob ${ }^{3}$, Xinfang Lu ${ }^{4}$, Matthew Rodland ${ }^{4}$, Leonardo Pereira ${ }^{2}$ \\ Drew W. Sadowsky ${ }^{1}$, Charles T. Roberts Jr. ${ }^{4}$, Miles J. Novy ${ }^{1,2}$, and Srinivasa R. Nagalla 3,4 \\ 1 Division of Reproductive Sciences, Oregon National Primate Research Center, Beaverton, OR
}

2Departments of Obstetrics \& Gynecology, Oregon Health and Science University, Portland, OR

4Pediatrics, Oregon Health and Science University, Portland, OR

3ProteoGenix Inc., Portland, OR

\begin{abstract}
Intra-amniotic infection (IAI) is associated with preterm birth and perinatal mortality. To identify potential biomarkers, we performed a comprehensive survey of cervical-vaginal fluid (CVF) proteome from a primate IAI model utilizing Multidimensional protein identification technology (LC/LC-MS/MS) and MALDI-TOF-MS analyses. Analyses of CVF proteome identified 205 unique proteins and differential expression of 27 proteins in controls and IAI samples. Protein expression signatures and immunodetection of specific biomarkers identified can be employed for non-invasive detection of IAI.
\end{abstract}

\section{INTRODUCTION}

Intrauterine infections, including intra-amniotic infections and chorioamnionitis, are an important and potentially preventable cause of maternal and perinatal mortality and morbidity 1. Intra-amniotic infection (IAI), in particular, accounts for up to $40 \%$ of cases of febrile morbidity in the peri-partum period, and is associated with at least one-third of early neonatal sepsis and pneumonia 2 . More recently, IAI has been implicated as a major cause of preterm birth. Despite improvements in prenatal care, preterm birth still occurs in $12.3 \%$ of births in the United States and remains the major obstetrical problem in developed countries ${ }^{3}$. Intraamniotic infections are associated with more than $50 \%$ of the very-low-birth-weight neonates that account for the highest number of neonatal deaths, the most serious complications, including neurologic handicap, and a disproportionate share of perinatal health care costs 1 . Accurate and early diagnosis of IAI would facilitate timelier and more appropriate interventions, as well as enhance the design of therapeutic trials. Early diagnosis of IAI is problematic, however, because clinical signs and symptoms tend to be late manifestations of this condition. Furthermore, the available noninvasive tests, e.g., maternal white blood cell

Correspondence: Michael G. Gravett, M.D., Department of Obstetrics \& Gynecology, University of Washington, 1959 NE Pacific St, Box 356460, Seattle, WA 98195, Email: gravettm@u.washington.edu.

Financial Disclosure

Oregon Health \& Science University and Drs. Gravett, Roberts, and Nagalla all have a significant financial interest in ProteoGenix, Inc., a company that may have a commercial interest in the results of this research and technology. This potential conflict of interest has been reviewed and a management plan approved by the OHSU Conflict of Interest in Research Committee. 
count or C-reactive protein, have limited predictive value, or, in the case of more predictive tests of amniotic fluid, e.g., interleukin-6, polymerase chain reaction, or microbial culture, the results are often delayed and amniocentesis is required 4,5 .

We have previously demonstrated, in a non-human primate model, the causal relationships among experimental IAI with Group B streptococcus, Ureaplasma parvum, or Mycoplasma hominis, and preterm birth 6,7 . We have also identified a distinct proteomic profile in amniotic fluid (AF) of both rhesus monkeys with experimental IAI and from a cohort of women with preterm labor ${ }^{8}$. Our objective in the current study was to extend these studies to a proteomic analysis of cervical-vaginal fluid (CVF). Our interest in CVF was based upon the non-invasive nature of obtaining specimens from a readily available site and previous observations that determination of CVF pro-inflammatory cytokines and fetal fibronectin have been utilized to identify women at risk of preterm delivery or IAI ${ }^{9-12}$. These currently available tests have limited predictive value for IAI, however, because they may also be influenced by the inflammatory microenvironment of the vaginal milieu. We sought to determine if proteomic evaluation of biomarkers previously identified in AF might also be reflected in CVF in the setting of experimental IAI in a non-human primate model.

In this study, we utilized multidimensional liquid chromotography coupled to tandem mass spectrometry (Multi-dimensional Protein Identification Technology; MudPIT) and spectral counting to characterize the proteins present in CVF and to determine the relative abundance of these proteins to detect the early appearance of sensitive and specific protein markers for IAI in CVF in non-human primates with experimental IAI caused by Ureaplasma parvum. In addition, we utilized matrix-assisted laser desorption/ionization time-of-flight mass spectrometry (MALDI-TOF-MS) to examine IAI-specific protein signatures in CVF and to compare them to signatures that we have previously described in AF.

\section{METHODS}

\section{Experimental IAI in non-human primates}

This protocol was approved by the Institutional Animal Care and Utilization Committee of Oregon Health \& Science University. Four pregnant rhesus monkeys (Macaca mulatta) with timed gestations were chronically catheterized at 120 days gestation (term is 167 days) as previously described ${ }^{6}$. Experimental IAI was established by intra-amniotic inoculation of $10^{7}$ colony-forming units of a clinical low-passage Ureaplamsa parvum, serovar 1, grown in $10 \mathrm{~B}$ culture media ${ }^{7}$. Each animal served as its own control. Before and after inoculation, AF and CVF samples were serially collected for quantitative bacterial cultures, white blood cell analysis, and cytokine and prostaglandin concentrations, as previously reported 6,7 , and for proteomic analysis. CVF was collected from the posterior vaginal fornix with sterile Dacron swabs (Solon, catalogue \#36816), which were then placed into phosphate-buffered saline containing a protease inhibitor cocktail (Roche Diagnostics, catalogue \#11836), to prevent nonspecific proteolysis from naturally occurring proteases within the vagina). Following protein extraction, samples were centrifuged to remove cellular debris and the supernatant stored at $-70^{\circ} \mathrm{C}$ until assayed. For these assays, pooled CVF samples were utilized from samples obtained prior to infection and from 24-72 hours after infection. Uterine contractility was recorded as the area under the amniotic fluid pressure curve and expressed as the hourly contraction area (HCA; mmHg times second/per). Fetal, decidual, placental, and bacterial cultures were obtained after delivery, by Cesarean, from infected animals to confirm infection, and histopathologic studies were performed to confirm histologic chorioamnionitis. 


\section{MALDI-TOF-MS profiling of CVF and AF}

A total of $0.5-3.0 \mu \mathrm{g}$ of unfractionated protein from CVF and AF was analyzed on a MALDITOF-TOF mass spectrometer (AutoFLEX II TOF/TOF, Bruker Daltonics, Billerica, MA) equipped with a pulsed-ion extraction source. Briefly, $1 \mu \mathrm{l}$ of sample was diluted with $4 \mu \mathrm{l}$ of $50 \%$ acetonitrile (ACN)/ $0.1 \%$ trifluoroacetic acid (TFA) and $5 \mu$ of matrix solution (saturated sinapinic acid in 50\% ACN/0.5\% TFA). Samples were spotted ( $2 \mu \mathrm{l})$ in quadruplicate, onto a 382-well ground steel Scout target (Bruker Daltonics, Billerica, MA). The Autoflex was used in linear mode with an accelerating voltage of $+20 \mathrm{kV}$. The pulsed-ion extraction drop voltage was $1500 \mathrm{~V}$ with a delay time of $350 \mathrm{~ns}$. Matrix ions were suppressed up to $3000 \mathrm{Da}$ using the maximum ion gating setting. The sampling rate was $2.0 \mathrm{GHz}$, and each profile spectrum represents a sum of 500 laser shots fired at 10 different positions. A nitrogen laser $(\lambda=337 \mathrm{~nm})$ operating at $50 \mathrm{~Hz}$ was used to irradiate samples. The output energy of the laser was $\sim 110$ $\mu \mathrm{J}$ attenuated with an offset of $62 \%$ and a range of $36 \%$. Samples were irradiated at a laser power of $30 \%$ and standards at $20 \%$. Spectra were manually collected from $\mathrm{m} / \mathrm{z} 3000$ to 20000 at a fixed laser power. Spectra were calibrated by external calibration using Protein calibration standard I mixture (Bruker Daltonics, Billerica, MA) containing the following: insulin ( $\mathrm{m} / \mathrm{z}$ 5734.6), ubiquitin ( $\mathrm{m} / \mathrm{z}$ 8565.9), cytochrome c (m/z 12361.9), and myoglobin ( $\mathrm{m} / \mathrm{z} 16952.6)$, and analyzed using ClinProt software version 2.0 (Bruker Daltonics, Billerica, MA).

\section{One-dimensional PAGE coupled to LC-MS/MS analysis}

One hundred $\mu \mathrm{g}$ of CVF protein from control and infected samples was reduced with iodoacetamide and resolved on a Tris-tricine, 10-20\% gradient SDS-PAGE gel. The gel was stained with Coomassie blue R-250 and distinct bands from each lane were cut from the gel, destained, and digested in-gel with trypsin for 24 hours at $37^{\circ} \mathrm{C}$ using the method of Courchesne and Patterson ${ }^{13}$. Peptides were then extracted with $0.1 \%$ TFA and purified using Zip-Tip c18 pipette tips from Millipore. After in-gel digestion, samples were analyzed on a Q-Tof-2 mass spectrometer (Micromass UK Ltd, United kingdom) coupled to a CapLC (Waters, Inc.,

Milford, MA). Masses from 400 to 1500 Da were scanned for the MS survey, and masses of 50 to $1900 \mathrm{Da}$ were scanned for MS/MS. Data analysis for protein identification was done as described below in MudPIT analysis.

\section{MudPIT protein identification and spectral counting}

For CVF MudPIT analysis, $100 \mu \mathrm{g}$ from each of 4 control and infected samples were pooled to create a $0.4 \mathrm{mg}$ sample from each condition. Protein was dissolved in $100 \mu \mathrm{l}$ of digestion buffer containing $8 \mathrm{M}$ urea, $1 \mathrm{M}$ Tris base, $80 \mathrm{mM}$ methylamine, and $8 \mathrm{mM} \mathrm{CaCl}_{2}(\mathrm{pH} 8.5)$. For reduction and alkylation of cysteine residues, samples were first incubated at $50^{\circ} \mathrm{C}$ in 12.5 $\mu \mathrm{l}$ of $0.9 \mathrm{M}$ DTT for $15 \mathrm{~min}$. and then in $25 \mu \mathrm{l}$ of $1.0 \mathrm{M}$ iodoacetamide in the dark at room temperature for another $15 \mathrm{~min}$. Before adding $40 \mu \mathrm{l}$ of mass spectrometry-grade trypsin (1 $\mu \mathrm{g} / \mu \mathrm{l}$; Promega, Madison WI), an additional $12.5 \mu \mathrm{l}$ of 0.9 M DTT along with $210 \mu \mathrm{l}$ of water and $1 \mathrm{~N} \mathrm{NaOH}$ to adjust the solution to $\mathrm{pH} 8.5$ was added. Samples were then thoroughly mixed and incubated overnight at $37^{\circ} \mathrm{C}$. Digestion was halted by the addition of $40 \mu \mathrm{l}$ of formic acid. Digests were desalted prior to MudPIT analysis using C18 Sep-Pak cartridges (Waters, Inc., Milford, MA).

Desalted digests $(1 \mathrm{ml})$ were injected onto a polysulfoethyl strong cation exchange column ( $2.1 \mathrm{~mm}$ ID $\times 100 \mathrm{~mm}, 5 \mu \mathrm{m}$ particles and $300-\mu$ pore size (Nest Group, Southborough, MA), and fractionated using an HPLC equipped with a UV detector and a fraction collector. Solvent A was $5.6 \mathrm{mM}$ potassium phosphate $(\mathrm{pH} 3)$ with $25 \%$ acetonitrile (ACN), and Solvent B was $5.6 \mathrm{mM}$ potassium phosphate $(\mathrm{pH} 3)$ and $350 \mathrm{mM} \mathrm{KCl}$ with $25 \% \mathrm{ACN}$. A 95-min. gradient at a flow rate of $200 \mu \mathrm{l} / \mathrm{min}$ was employed for fractionation of peptides: $100 \% \mathrm{~A}$ for $10 \mathrm{~min}$., ramp to $50 \% \mathrm{~B}$ over $45 \mathrm{~min}$., ramp to $100 \% \mathrm{~B}$ over $15 \mathrm{~min}$., and ramp back to $100 \% \mathrm{~A}$ in $0.1 \mathrm{~min}$., hold at $100 \% \mathrm{~A}$ for $20 \mathrm{~min}$. A total of 80 fractions were collected and stored at $-20^{\circ}$ 
C. The fractions were evaporated and resuspended in $100 \mu \mathrm{l}$ of $0.1 \%$ TFA for desalting using a 96-well spin column (Vydac C18 silica: Nest Group, Southborough, MA). After elution in $80 \% \mathrm{ACN} / 0.1 \%$ formic acid (FA), fractions were consolidated into 43 fractions, evaporated, and resuspended in $25 \mu \mathrm{l}$ of $5 \%$ FA.

SCX fractions ( $5 \mu$ l each) were analyzed on a Q-Tof- 2 mass spectrometer connected to a CapLC (Waters Inc., Milford, MA). The Q-Tof-2 was equipped with a nanospray source. Each SCX fraction was separated using a Nanoease $\mathrm{C} 1875 \mu \mathrm{m}$ ID $\times 15 \mathrm{~cm}$ fused silica capillary column (Waters Inc., Milford, MA) and a 95-min water/ACN gradient. The mass spectrometer was calibrated using Glu1Fibrinopeptide B. An MS/MSMS survey method was used to acquire spectra. Masses from $\mathrm{m} / z 400$ to 1500 were scanned for MS survey and masses from $\mathrm{m} / z 50$ to 1900 for MSMS. MS/MS spectra were processed with ProteinLynx Global Server v.2.1 software (Waters Inc., Milford, MA).

A total of 3,120 MS/MS spectra from control samples and 2,800, MS/MS spectra from IAI samples were searched against a combined database containing known contaminants and forward and reverse entries of the Swiss-Prot human database (version 46.6) using three independent search engines: OpenSea 14,15 , TurboSequest (ThermoFinnigan, Waltham, MA), and X! Tandem 16. PEAKS software (Bioinformatics Solutions, Ontario, CA) was used to generate de novo sequences for the OpenSea search engine. Protein identifications from individual search engine results were combined using probabilistic protein identification algorithms implemented in Scaffold software (Proteome Software, Portland, OR). 52\% of the spectra from the control sample and $50 \%$ of the spectra from the IAI sample were assigned to proteins with at least one confident peptide (probability $\geq 0.8$ ) identification. Protein identifications having at least two independent peptide identifications (probability $\geq 0.8$ ) were considered likely to be present in the sample.

\section{Polyclonal antibodies and western immunoblotting}

Immunogenic peptides and/or recombinant proteins were used to generate rabbit and goat polyclonal antibodies (DSL Laboratories, Webster, TX). Affinity-purified antibodies were then used for western blots. One hundred $\mu \mathrm{g}$ of CVF protein was resolved on 4-20\% SDS-PAGE and transferred to PVDF membranes. The membranes were blocked with $5 \%$ fat-free milk in PBST for $45 \mathrm{~min}$ at room temperature and incubated with $1 \mu \mathrm{g} / \mathrm{ml}$ primary antibody (IGFBP-1, Azurocidin, Calgranulin-A, Calgranulin-B, Anexin II, Lipocalin, Profilin) overnight at $4^{\circ} \mathrm{C}$. After three washes with TBST, the membrane was incubated with IgG-HRP secondary antibody (Sigma-Aldrich Co.) and visualized with enhanced chemiluminescence (Pierce).

\section{Statistical analysis}

Spectral counting was used to determine the proteins that were differentially expressed between control and infected MudPIT samples. All proteins with more than two confident peptide identifications were considered for protein quantification using spectral counting. Identified protein lists were further curated by collapsing spectral counts for similar proteins $($ e.g., immunoglobulins, $\alpha-1$-acid-glycoproteins 1 and 2 , and pregnancy-specific glycoproteins) into a single entry. Spectral counts of identical peptides between dissimilar proteins were split between the proteins in equal ratios. Curated protein lists for both samples were merged and an independent $2 \times 2 \chi^{2}$ test on the spectral counts for each protein between the samples was used to find proteins that were differentially present between them. In order to reduce the falsepositive rate of differentially abundant proteins, only proteins with a $p$-value $\leq 0.1$ and with at least two independent peptides matched to at least four MS/MS spectra (probability $\geq 0.8$ ) in at least one of the samples were considered as statistically significant. Fold changes of proteins passing the above criteria were determined using a published formula for calculating spectral count ratios 17 . 


\section{RESULTS}

\section{Experimental IAI following Ureaplasma parvum infection}

Following intra-amniotic inoculation, infection was rapidly established in all animals. Increases in uterine contractility from basal levels of 100 HCA to levels in excess of 3,0006,000 HCA occurred an average of 54 (range 34-72) hours after inoculation with Ureaplasma parvum, and led to progressive cervical changes, as measured by the Bishop score. Increases in uterine contractility were preceded by significant elevations in the pro-inflammatory cytokines TNF- $\alpha$, IL-1 $\beta$, IL-6, and IL-8, and prostaglandins $E_{2}$ and $F_{2 \alpha}$ as previously reported 6,7 . No animal had other clinical signs of IAI at the time of initial increases in uterine contractility. Following delivery, histopathologic examination confirmed chorioamnionitis in all cases.

\section{Global analysis of the CVF proteome in a non-human primate experimental IAI model using multidimensional protein identification technology (MudPIT)}

Increasing confidence in mass spectrometry-based peptide identification and quantification methods has launched the development of extensive and varied multidimensional peptide separations coupled with MS/MS. Such "shotgun" peptide sequencing endeavors produce reliable protein identifications, as well as relative quantitative information for comparing sets of samples analyzed in parallel.

A total of 205 unique proteins (supplementary table 1) were identified in CVF using MudPIT and gel-based fractionation (1D PAGE coupled to LC-Tandem mass spectrometry) analyses. Functional annotation of the CVF proteome using GeneOntology terms (DAVID V 2.1) showed (Figure 1A) a majority of them to be associated with metabolism (25\%) and immune response $(23 \%)$. Analysis of the predicted sub-cellular location of the proteins identified from CVF (Figure 1B) showed that the annotated proteins are from cytoplasmic $(24 \%)$, secretory $(18 \%)$, cytoskeletal $(14 \%)$, and nuclear $(14 \%)$ categories. No information was available regarding the cellular location of $13 \%$ of the proteins identified.

For the analysis of differential protein levels in the setting of infection, CVF samples obtained before and after experimental IAI were digested with trypsin and subjected to MudPIT analysis. MS/MS spectra derived from the MudPIT analysis led to the high-confidence identification (2 or more peptides/protein) of 149 and 151 proteins in the control and infected samples, respectively. To decrease false-positive protein identification rates, MS/MS spectra were searched against a database containing known contaminants (i.e., trypsin, keratin, and serum albumin) and both forward and reverse peptide sequence entries from the Swiss-Prot human and primate databases using three independent search engines. A probability-based algorithm, Scaffold (Proteome Software Inc., Portland, OR), was used to combine results from the three search engines. The use of multiple searching algorithms increases the confidence in reported identifications by decreasing peptide identifications occurring by chance. Protein identification numbers reported above had two or more unique peptide identifications.

For quantitative comparison of control and IAI samples, a spectral counting method was implemented. Spectral counting permits rapid detection of abundance differences between two sample pools without resorting to complicated differential labeling experimentation (Zybailov 2005). Curated protein lists from control and IAI were compiled, and independent $\chi^{2}$ tests on the spectral counts of each protein were performed. Proteins with calculated $\chi^{2}$ values over 2.706 (90\% confidence interval) are reported in Table 1 . Included in the table are the spectral counts and the number of MS/MS peptide spectra matching to the given protein, for the control and IAI samples. The fold change between control and IAI for each of the significant proteins was also calculated ${ }^{17}$. Of the 27 proteins found to be differentially present between control 
and IAI by spectral counting, 19 proteins had $\chi^{2}$ values in the $99 \%$ confidence interval, and 8 proteins had $\chi^{2}$ values in the $95 \%$ confidence interval. When compared to quantitative proteomic studies performed using protein separations (1D PAGE LC-MS/MS), 15 proteins found by spectral counting corresponded to differential trends seen in 1-D gel-based experiments. The identification of potential lower-abundance serum protein markers is one of the benefits of MudPIT analysis. The multi-dimensional front-end peptide separations (SCX and RP-LC) permit the interrogation of a wider dynamic range of concentration over gel-based proteomic analyses as well as MALDI profiling technologies.

The potential biomarkers for detection of IAI in CVF, summarized in Table 1, were predominantly immunoregulatory proteins. Several of these, including calgranulins A and B, azurocidin, and IGFBP- 1 , which were differentially present in IAI AF ${ }^{8}$, were also found to be up-regulated in IAI CVF. The differential abundance of total IGFBP-1 (Table 1) reflected both the intact 30-kDa protein and a proteolytic fragment, identified by Western blot in Figure 2. However, the majority of IGFBP-1 present in the setting of IAI was comprised of the proteolytic fragment (Figure 2). Defensins, previously identified by others as markers for intraamniotic or lower genital tract infections ${ }^{18-20}$, were also identified in the 3-5-kDa peak. However, their differential presence in control and IAI CVF did not achieve statistical significance by spectral analysis. Of interest, the basal levels of some of the immunoregulatory peptides were higher in CVF compared to AF, consistent with a more chronically inflammatory milieu in the microbial rich lower genital tract than in the normally sterile amniotic cavity.

\section{Identification of IAI protein profiles by MALDI-TOF MS}

MALDI-TOF MS analyses of CVF and AF protein extracts revealed several peak intensity differences in 3-5-kDa and 11-12-kDa regions between infected and non-infected primate and human $\mathrm{CVF}$ and $\mathrm{AF}$ (Figure 2), similar to the previously reported protein signature profile in AF obtained by SELDI-TOF 8 .

A 10.8-kDa cluster was consistently up-regulated in infected CVF and amniotic fluid in all cases. Of interest, the relative intensity of this peak was greater among CVF samples than among AF samples following infection, consistent with the hypothesis that the basal state of the lower genital tract milieu is pro-inflammatory. The increased expression of the 3-5-kDa cluster in response to IAI is more robust in AF compared to CVF. The proteins with masses 3432 and 4128 Da were commonly over-expressed in AF and CVF in the presence of IAI. These masses may represent defensins, as reported earlier ${ }^{18}$. Longitudinal sampling following Ureaplasma parvum infection revealed that the $10.8-\mathrm{kDa}$ cluster intensity was increased as early as 24 hours after inoculation, and preceded increases in HCA in infected animals in both CVF and AF samples (data not shown).

\section{Immunodetection of IAI biomarkers}

To validate the differential expression of proteins identified in IAI, we selected 5 of the markers identified from MudPIT analysis. Antibodies were raised for Calgranulins A and B, IGFBP-1, Azurocidin, Lipocalin, Annexin II, and an unregulated protein (Haptoglobin) to confirm the differential abundance of potential IAI biomarkers. As shown in Figure 3, western blot analysis confirmed the differential presence of all of these biomarkers, which exhibited differential levels that were consistent with the protein identification experiments performed on IAI CVF.

\section{DISCUSSION}

Subclinical IAI is present in at least $50 \%$ of extremely premature births, in which neonatal morbidity and mortality are disproportionately high ${ }^{1}$. The early clinical diagnosis of IAI is made difficult by the fact that signs and symptoms of IAI are a late manifestation of the 
infection. Furthermore, the available non-invasive diagnostic tests (e.g., maternal white blood cell count or C-reactive protein) have limited predictive value. Other tests, including measurement of AF glucose, leukocytes, interleukin-6, or Gram stain require amniocentesis, and additionally, in the case of AF culture, the results are delayed beyond a clinically optimal timeframe.

A causal relationship between IAI and preterm delivery that parallels the course observed in women has been demonstrated in a non-human primate experimental model ${ }^{6}$. In a previous study, we utilized SELDI-TOF mass spectrometry to characterize protein profiles in AF from rhesus monkeys with experimental IAI and in women with subclinical IAI and preterm delivery 8 . We identified a unique SELDI-TOF profile with elevated levels of peptides in the 3-5-kDa and in the 10.8-kDa molecular weight ranges in all AF samples after infection, and in no AF obtained prior to infection. Similarly, this unique protein profile was observed in all women with IAI and preterm delivery, and in no women with preterm labor without infection and subsequent delivery at term ${ }^{8}$. Proteins identified by tandem mass spectrometry within these mass ranges included calgranulins A and B and a unique proteolytic fragment of IGFBP-1. These findings have recently been confirmed, and other protein biomarkers of IAI identified, by Buhimschi, et al. 18 .

In the present study, we sought first to characterize the proteome of CVF and to characterize and to compare with AF, the protein profile in CVF from rhesus monkeys with experimental IAI utilizing the same experimental model as previously described ${ }^{6-8}$. This is the first report utilizing MALDI-TOF mass spectrometry and multidimensional protein identification technology (MudPIT) to characterize the protein profile of CVF and to identify novel biomarkers for IAI in a site that allows for non-invasive collection of serial samples from a more accessible maternal sampling site. This may allow for the risk prediction or diagnosis of ascending intrauterine infection in the etiology of IAI and, by comparison with maternal serum and fetal AF sampling, provide new insights into the pathogenesis of IAI. We utilized a wellestablished, non-human primate model in which experimental IAI was caused by intraamniotic inoculation of Ureaplasma parvum. We chose this pathogen because the most frequently isolated microorganisms from placentae of women with histologic chorioamnionitis 21 or from AF of women in preterm labor with intact fetal membranes (Yoon, 1998) are Ureaplasma species ( $U$. urealyticum and $U$. parvum). Ureaplasma species have also been implicated in postpartum endomyometritis, neonatal sepsis, meningitis, and neonatal bronchopulmonary dysplasia $22-24$.

We utilized two very distinct proteomic approaches in this study: a rapid protein fingerprinting approach (MALDI-TOF MS) that generates distinct expression profiles and is amenable for developing rapid screening assays, together with a in-depth protein identification and quantification approach (LC-LC-MS/MS, MudPIT) that provides the identity of the biomarkers suitable for identification by conventional immunoassays. MALDI-TOF-MS-based profiling techniques have been targeted for their robustness, ease-of-use, and high-throughput nature. The majority of profiling studies to date have evaluated disease states using MALDI-MS protein profiling methods involving serum fractionation using chromatographic techniques coupled with MALDI-TOF-MS $25-27$. While the MS protein profiles from these studies may have identified unique masses capable of discriminating between normal and perturbed samples, the methodologies used are unable to identify and validate found protein classifiers based solely upon the MALDI-MS protein $\mathrm{m} / \mathrm{z}$ value.

Two-dimensional gel electrophoresis (2-DE) commonly used to detect differential protein expression patterns 28,29 is biased towards detection of high-abundance proteins, with limited capabilities to detect low-abundance proteins ${ }^{30}$. Advances in multidimensional LC approaches coupled to MS/MS (Multi-dimensional Protein Identification Technology, 
MudPIT) have enabled better sample enrichment, separation, and in-depth peptide coverage to study global protein expression changes from tryptic digests of complex mixtures $31-35$. Recently, MS/MS spectral sampling from complex peptide mixtures has been identified as a source of relative quantitative information. Using spectral counting, the total number of peptide identifications in a complex peptide mixture analyzed by MudPIT was found to correlate linearly with protein abundance over a 100 -fold concentration range and to be more reproducible with a wider dynamic range over mass spectrometry-derived ion chromatograms $17,36,37$.

Characterization of proteins expressed in CVF in control and IAI using MudPIT analyses revealed a significant number of immune response/defense-related proteins that were upregulated in IAI. There is a considerable degree of overlap between the differentially abundant proteins in AF and CVF during IAI. In our study, calgranulins, azurocidin, lipocalin, L-plastin, and others, which were previously identified as potential biomarkers for IAI in amniotic fluid, were also differentially present in CVF. In addition to the above immunomodulators, the detection of the antibacterial protein azurocidin in CVF in response to infection provides new insights into the intrauterine immune response. Azurocidin (CAP37) is a cationic antimicrobial protein isolated from human neutrophils that has potentially important actions in host defense and inflammation ${ }^{38}$. Another antimicrobial protein with elevated expression in IAI is cathelin, which has a C-terminal 37-residue alpha-helical peptide active against bacterial infection.

39 . The increased levels of annexins in infected CVF may relate to CVF-specific IAI responses. Annexins are a group of $\mathrm{Ca}^{+}$-binding proteins that are associated with inflammatory and defense responses. Annexin A2 is up-regulated in viral-transformed cell lines and in human tumors 40 . Annexin 1 modulates the anti-inflammatory actions of the steroid hormones 41 . Matrix metalloproteinases (MMPs) are a family of zinc-dependent endopeptidases that are expressed in many inflammatory conditions and contribute to connective tissue breakdown. It has been proposed that bacterial products and/or the proinflammatory cytokines IL-1beta and TNF-alpha, as paracrine or autocrine signals, may trigger amniochorion cells to induce MMP expression 42,43 .

In the second approach, we utilized MALDI-TOF MS and detected a significantly overexpressed 10.8-kDa cluster in CVF in the setting of experimental primate IAI. This is similar to the AF proteome profile observed in our previous studies ${ }^{8}$, and confirms the specificity of this signature profile for the detection of IAI in CVF. This over-expressed cluster could represent the basic intrauterine immune response to infection, as one set of proteins identified in this unique cluster, i.e., the calgranulins, are members of the S-100 calcium binding protein family that is expressed by macrophages and by epithelial cells in acutely inflamed tissues. The second candidate from this cluster, a proteolytic fragment of IGFBP-1, indicates a potential protease-related mechanism in response to infection. Intact IGFBP-1 is the major IGFBP found in AF, and is synthesized by both fetal membranes and maternal decidua. Notably, however, this signature is present, albeit in lower relative concentrations, in CVF samples, but absent in AF samples prior to infection. The higher basal levels of these immunoregulatory peptides may reflect the basal inflammatory characteristics of the vaginal milieu compared to that of amniotic fluid. Amniotic fluid is normally sterile, with minimal concentrations of inflammatory markers. In contrast, the vagina is characterized by a pro-inflammatory, microbe-rich environment. Thus, while CVF samples may have the advantage of ease of non-invasive sampling, the results may be confounded by local inflammatory conditions such as bacterial vaginosis.

Characterization of the CVF proteome and identification of a significant number of proteins differentially expressed in IAI complements the sensitive proteomic approaches used to identify biomarkers and their potential value in development of non-invasive testing for IAI. Much can be learned about the pathogenesis of IAI by analysis of temporal and quantitative samples from CVF, AF, and maternal serum. Analogous issues have been raised by surveys 
of other cervical-vaginal inflammatory biomarkers such as pro-inflammatory cytokines and fetal fibronectin $9-12$. These observations, and ours, are consistent with the hypothesis that, during infection-associated preterm birth, there is a disruption of the extracellular matrix at the choriodecidual interface, and that inflammatory mediators produced at this interface reach the vaginal pool, possibly in association with a breakdown in cervical barriers.

In summary, we utilized two complimentary proteomic approaches to characterize the global expression of cervical-vaginal proteins and to identify potential biomarkers of IAI in cervical vaginal fluid. Distinct immunoregulatory peptides were identified that were differentially expressed in CVF following experimental IAI. The differential expression of these peptides was confirmed with immunoassay, and provides an opportunity for the development of noninvasive reliable tests for the diagnosis of IAI.

\section{Supplementary Material}

Refer to Web version on PubMed Central for supplementary material.

\section{Acknowledgements}

Supported in part by NIH Grants AI42490 and HD06159 and by ProteoGenix, Inc.

\section{References}

1. Goldenberg RL, Hauth JC, Andrews WW. Intrauterine infection and preterm delivery. N Engl J Med 2000;342(20):1500-7. [PubMed: 10816189]

2. Newton ER. Chorioamnionitis and intraamniotic infection. Clin Obstet Gynecol 1993;36(4):795-808. [PubMed: 8293582]

3. Martin JA, Hamilton BE, Sutton PD, Ventura SJ, Menacker F, Munson ML. Births: final data for 2003. Natl Vital Stat Rep 2005;54(2):1-116.

4. Hitti J, Riley DE, Krohn MA, Hillier SL, Agnew KJ, Krieger JN, Eschenbach DA. Broad-spectrum bacterial rDNA polymerase chain reaction assay for detecting amniotic fluid infection among women in premature labor. Clin Infect Dis 1997;24(6):1228-32. [PubMed: 9195088]

5. Watts DH, Krohn MA, Hillier SL, Eschenbach DA. The association of occult amniotic fluid infection with gestational age and neonatal outcome among women in preterm labor. Obstet Gynecol 1992;79 (3):351-7. [PubMed: 1738513]

6. Gravett MG, Witkin SS, Haluska GJ, Edwards JL, Cook MJ, Novy MJ. An experimental model for intraamniotic infection and preterm labor in rhesus monkeys. Am J Obstet Gynecol 1994;171(6):16607. [PubMed: 7802084]

7. Novy, MJ.; Duffy, L.; Axthelm, MK.; Cook, MJ.; Haluska, GJ.; Witkin, SS.; Gerber, S.; Gravett, MG.; Sadowsky, DW.; Cassell, GH. Experimental primate model for Ureaplasma chorioamnionitis and preterm labor. Society for Gynecologic Investigation, 2001; Toronto, Canada. March 14-17, 2001;

8. Gravett MG, Novy MJ, Rosenfeld RG, Reddy AP, Jacob T, Turner M, McCormack A, Lapidus JA, Hitti J, Eschenbach DA, Roberts CT Jr, Nagalla SR. Diagnosis of intra-amniotic infection by proteomic profiling and identification of novel biomarkers. Jama 2004;292(4):462-9. [PubMed: 15280344]

9. Rizzo G, Capponi A, Rinaldo D, Tedeschi D, Arduini D, Romanini C. Interleukin-6 concentrations in cervical secretions identify microbial invasion of the amniotic cavity in patients with preterm labor and intact membranes. Am J Obstet Gynecol 1996;175(4 Pt 1):812-7. [PubMed: 8885727]

10. Holst RM, Mattsby-Baltzer I, Wennerholm UB, Hagberg H, Jacobsson B. Interleukin-6 and interleukin-8 in cervical fluid in a population of Swedish women in preterm labor: relationship to microbial invasion of the amniotic fluid, intra-amniotic inflammation, and preterm delivery. Acta Obstet Gynecol Scand 2005;84(6):551-7. [PubMed: 15901266]

11. Di Naro E, Ghezzi F, Raio L, Romano F, Mueller MD, McDougall J, Cicinelli E. C-reactive protein in vaginal fluid of patients with preterm premature rupture of membranes. Acta Obstet Gynecol Scand 2003;82(12):1072-9. [PubMed: 14616249] 
12. Yoon BH, Romero R, Moon JB, Oh SY, Han SY, Kim JC, Shim SS. The frequency and clinical significance of intra-amniotic inflammation in patients with a positive cervical fetal fibronectin. Am J Obstet Gynecol 2001;185(5):1137-42. [PubMed: 11717647]

13. Courchesne PL, Patterson SD. Identification of proteins by matrix-assisted laser desorption/ionization mass spectrometry using peptide and fragment ion masses. Methods Mol Biol 1999;112:487-511. [PubMed: 10027273]

14. Searle BC, Dasari S, Turner M, Reddy AP, Choi D, Wilmarth PA, McCormack AL, David LL, Nagalla SR. High-throughput identification of proteins and unanticipated sequence modifications using a mass-based alignment algorithm for MS/MS de novo sequencing results. Anal Chem 2004;76(8): 2220-30. [PubMed: 15080731]

15. Searle BC, Dasari S, Wilmarth PA, Turner M, Reddy AP, David LL, Nagalla SR. Identification of protein modifications using MS/MS de novo sequencing and the OpenSea alignment algorithm. J Proteome Res 2005;4(2):546-54. [PubMed: 15822933]

16. Craig R, Cortens JP, Beavis RC. Open source system for analyzing, validating, and storing protein identification data. J Proteome Res 2004;3(6):1234-42. [PubMed: 15595733]

17. Old WM, Meyer-Arendt K, Aveline-Wolf L, Pierce KG, Mendoza A, Sevinsky JR, Resing KA, Ahn NG. Comparison of label-free methods for quantifying human proteins by shotgun proteomics. Mol Cell Proteomics 2005;4(10):1487-502. [PubMed: 15979981]

18. Buhimschi IA, Christner R, Buhimschi CS. Proteomic biomarker analysis of amniotic fluid for identification of intra-amniotic inflammation. Bjog 2005;112(2):173-81. [PubMed: 15663581]

19. Valore EV, Park CH, Quayle AJ, Wiles KR, McCray PB Jr, Ganz T. Human beta-defensin-1: an antimicrobial peptide of urogenital tissues. J Clin Invest 1998;101(8):1633-42. [PubMed: 9541493]

20. Balu RB, Savitz DA, Ananth CV, Hartmann KE, Miller WC, Thorp JM, Heine RP. Bacterial vaginosis and vaginal fluid defensins during pregnancy. Am J Obstet Gynecol 2002;187(5):1267-71. [PubMed: 12439518]

21. Hillier SL, Martius J, Krohn M, Kiviat N, Holmes KK, Eschenbach DA. A case-control study of chorioamnionic infection and histologic chorioamnionitis in prematurity. N Engl J Med 1988;319 (15):972-8. [PubMed: 3262199]

22. Chaim W, Horowitz S, David JB, Ingel F, Evinson B, Mazor M. Ureaplasma urealyticum in the development of postpartum endometritis. Eur J Obstet Gynecol Reprod Biol 2003;109(2):145-8. [PubMed: 12860331]

23. Viscardi RM, Manimtim WM, Sun CC, Duffy L, Cassell GH. Lung pathology in premature infants with Ureaplasma urealyticum infection. Pediatr Dev Pathol 2002;5(2):141-50. [PubMed: 11910508]

24. Yoon BH, Romero R, Kim M, Kim EC, Kim T, Park JS, Jun JK. Clinical implications of detection of Ureaplasma urealyticum in the amniotic cavity with the polymerase chain reaction. Am J Obstet Gynecol 2000;183(5):1130-7. [PubMed: 11084554]

25. Tang N, Tornatore P, Weinberger SR. Current developments in SELDI affinity technology. Mass Spectrom Rev 2004;23(1):34-44. [PubMed: 14625891]

26. Issaq HJ, Conrads TP, Prieto DA, Tirumalai R, Veenstra TD. SELDI-TOF MS for diagnostic proteomics. Anal Chem 2003;75(7):148A-155A.

27. Petricoin EF, Ardekani AM, Hitt BA, Levine PJ, Fusaro VA, Steinberg SM, Mills GB, Simone C, Fishman DA, Kohn EC, Liotta LA. Use of proteomic patterns in serum to identify ovarian cancer. Lancet 2002;359(9306):572-7. [PubMed: 11867112]

28. Tsangaris G, Weitzdorfer R, Pollak D, Lubec G, Fountoulakis M. The amniotic fluid cell proteome. Electrophoresis 2005;26(6):1168-73. [PubMed: 15706572]

29. Pieper R, Gatlin CL, Makusky AJ, Russo PS, Schatz CR, Miller SS, Su Q, McGrath AM, Estock MA, Parmar PP, Zhao M, Huang ST, Zhou J, Wang F, Esquer-Blasco R, Anderson NL, Taylor J, Steiner S. The human serum proteome: display of nearly 3700 chromatographically separated protein spots on two-dimensional electrophoresis gels and identification of 325 distinct proteins. Proteomics 2003;3(7):1345-64. [PubMed: 12872236]

30. Gorg A, Weiss W, Dunn MJ. Current two-dimensional electrophoresis technology for proteomics. Proteomics 2004;4(12):3665-85. [PubMed: 15543535] 
31. Washburn MP, Wolters D, Yates JR 3rd. Large-scale analysis of the yeast proteome by multidimensional protein identification technology. Nat Biotechnol 2001;19(3):242-7. [PubMed: 11231557]

32. Schirmer EC, Florens L, Guan T, Yates JR 3rd, Gerace L. Nuclear membrane proteins with potential disease links found by subtractive proteomics. Science 2003;301(5638):1380-2. [PubMed: 12958361]

33. Le Roch KG, Johnson JR, Florens L, Zhou Y, Santrosyan A, Grainger M, Yan SF, Williamson KC, Holder AA, Carucci DJ, Yates JR 3rd, Winzeler EA. Global analysis of transcript and protein levels across the Plasmodium falciparum life cycle. Genome Res 2004;14(11):2308-18. [PubMed: 15520293]

34. Peng J, Schwartz D, Elias JE, Thoreen CC, Cheng D, Marsischky G, Roelofs J, Finley D, Gygi SP. A proteomics approach to understanding protein ubiquitination. Nat Biotechnol 2003;21(8):921-6. [PubMed: 12872131]

35. Ideker T, Thorsson V, Ranish JA, Christmas R, Buhler J, Eng JK, Bumgarner R, Goodlett DR, Aebersold R, Hood L. Integrated genomic and proteomic analyses of a systematically perturbed metabolic network. Science 2001;292(5518):929-34. [PubMed: 11340206]

36. Liu H, Sadygov RG, Yates JR 3rd. A model for random sampling and estimation of relative protein abundance in shotgun proteomics. Anal Chem 2004;76(14):4193-201. [PubMed: 15253663]

37. Zybailov B, Coleman MK, Florens L, Washburn MP. Correlation of relative abundance ratios derived from peptide ion chromatograms and spectrum counting for quantitative proteomic analysis using stable isotope labeling. Anal Chem 2005;77(19):6218-24. [PubMed: 16194081]

38. Gabay JE, Scott RW, Campanelli D, Griffith J, Wilde C, Marra MN, Seeger M, Nathan CF. Antibiotic proteins of human polymorphonuclear leukocytes. Proc Natl Acad Sci U S A 1989;86(14):5610-4. [PubMed: 2501794]

39. Zhao C, Nguyen T, Boo LM, Hong T, Espiritu C, Orlov D, Wang W, Waring A, Lehrer RI. RL-37, an alpha-helical antimicrobial peptide of the rhesus monkey. Antimicrob Agents Chemother 2001;45 (10):2695-702. [PubMed: 11557457]

40. Filipenko NR, MacLeod TJ, Yoon CS, Waisman DM. Annexin A2 is a novel RNA-binding protein. J Biol Chem 2004;279(10):8723-31. [PubMed: 14672933]

41. Castro-Caldas M, Duarte CB, Carvalho AR, Lopes MC. 17beta-estradiol promotes the synthesis and the secretion of annexin I in the CCRF-CEM human cell line. Mediators Inflamm 2001;10(5):24551. [PubMed: 11759108]

42. Vadillo-Ortega F, Sadowsky DW, Haluska GJ, Hernandez-Guerrero C, Guevara-Silva R, Gravett MG, Novy MJ. Identification of matrix metalloproteinase-9 in amniotic fluid and amniochorion in spontaneous labor and after experimental intrauterine infection or interleukin-1 beta infusion in pregnant rhesus monkeys. Am J Obstet Gynecol 2002;186(1):128-38. [PubMed: 11810098]

43. Vadillo-Ortega F, Estrada-Gutierrez G. Role of matrix metalloproteinases in preterm labour. Bjog 2005;112(Suppl 1):19-22. [PubMed: 15715589] 
A

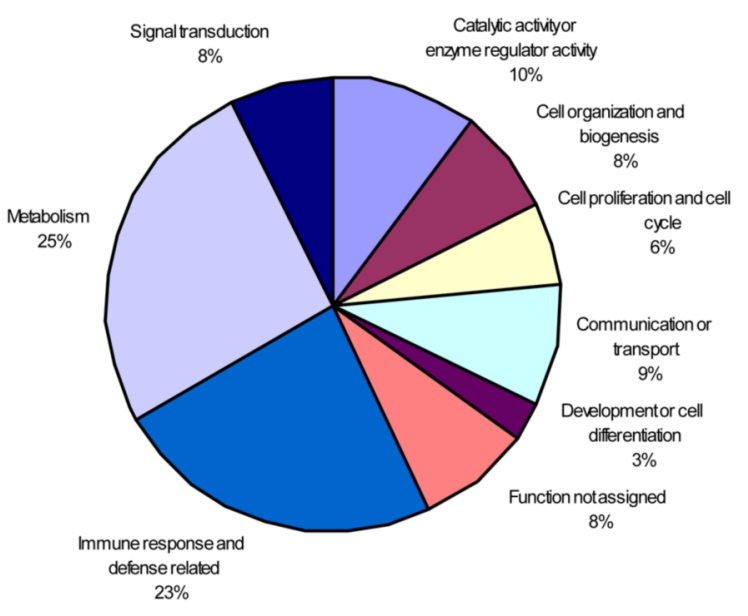

B

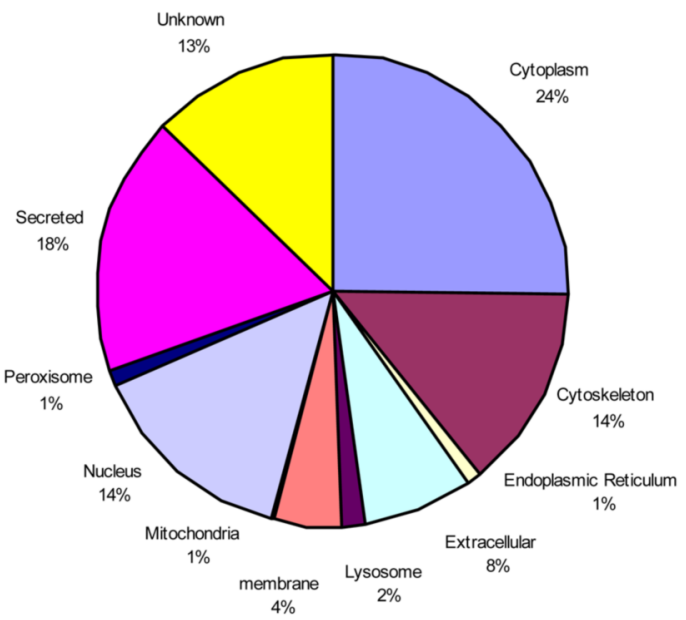

Figure 1.

A-B. Functional annotation and cellular localization of proteins expressed in CVF. Two hundred and five proteins identified utilizing MudPIT and gel-based fractionation were analyzed for GeneOntology terms (GO terms) using an annotation database (DAVID, Version 2.0 , NIAID). $8 \%$ of the total proteins did not show any known functional annotation. 

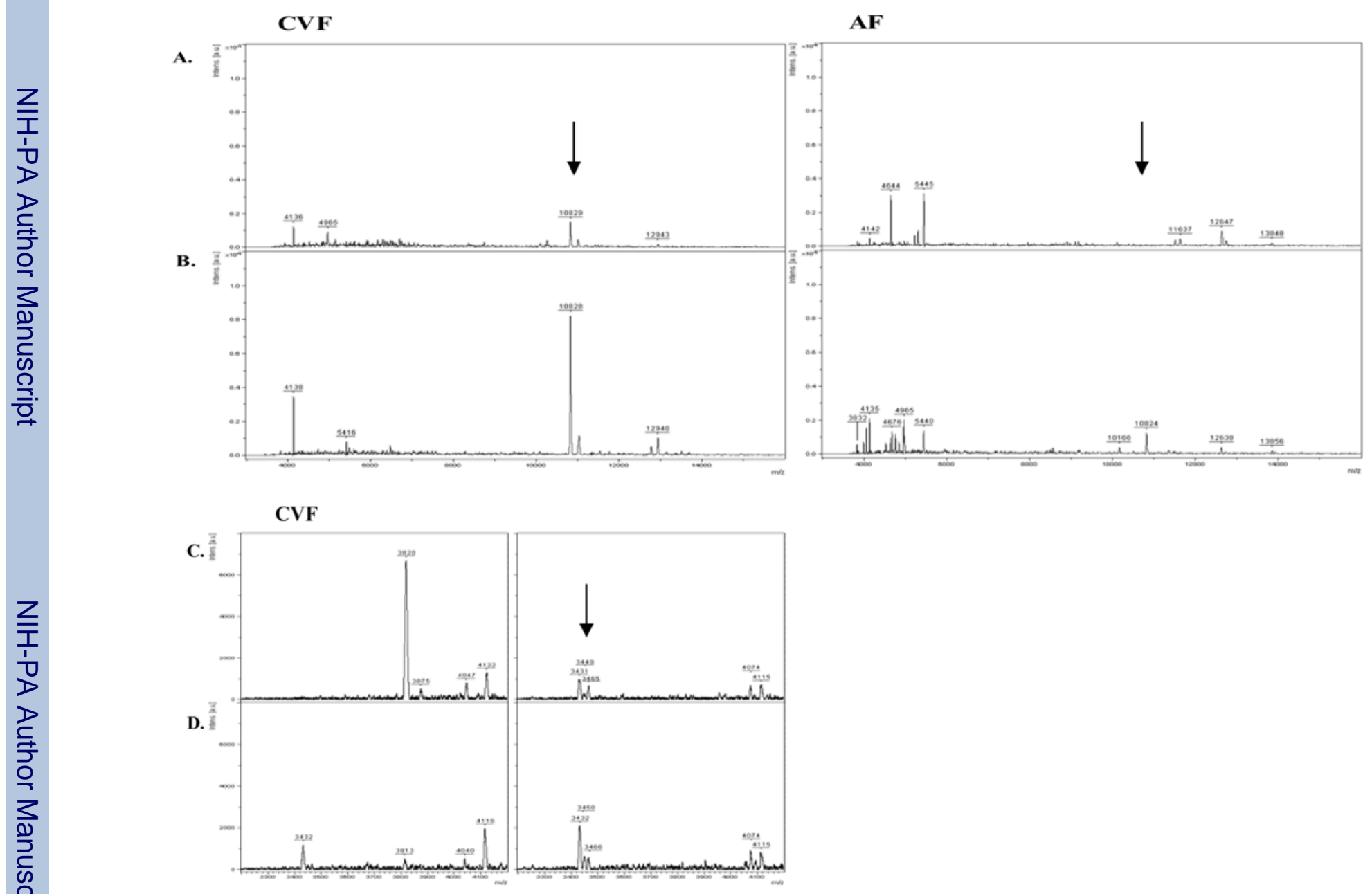

Figure 2.

A-D. Matrix-assisted laser desorption/ionization time-of-flight (MALDI-TOF-MS) protein profiles of Ureaplasma parvum-induced differential protein levels in non-human primate CVF and AF samples. Profiles demonstrating the 10.8-kDa peak are shown in control samples taken prior to (A) and following (B) experimental IAI. Profiles demonstrating peptides in the 3-5kDa MW range are shown in C) control samples taken prior to and D) samples taken following experimental IAI. Spectra were processed for baseline subtraction and Savitsky-Golay smoothing, 5 cycles at $10 \mathrm{Da} /$ channel. Spectra representing $\mathrm{m} / \mathrm{z}$ range from 3000 to 2000 are shown with arrows indicating differentially expressed peaks between control and infection. 


\section{Control Infected}

Calgranulin A

Calgranulin B

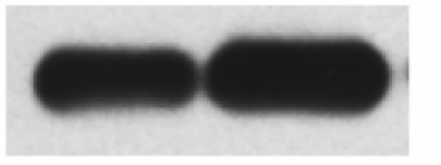

Axurocidin

Annexin II

Lipocalin

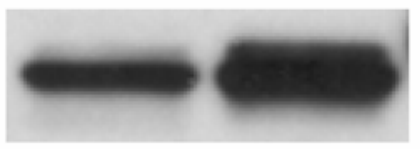

$26.8 \mathrm{kDa}$

$13 \mathrm{kDa}$

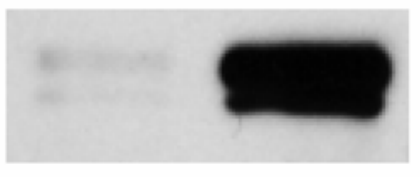

$38.5 \mathrm{kDa}$
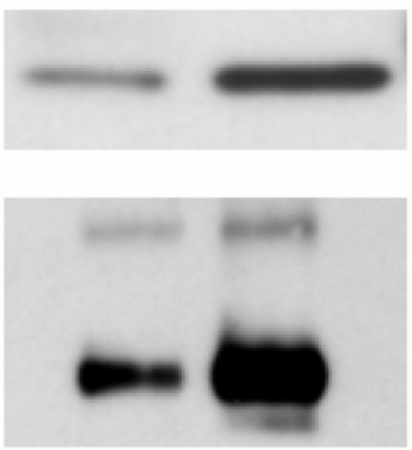

Haptoglobin

$10.8 \mathrm{kDa}$

$22.6 \mathrm{kDa}$

$30 \mathrm{kDa}$ Intact protein

IGFBPI

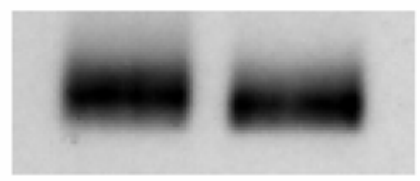

\section{$46 \mathrm{kDa}$}

Figure 3.

Immunodetection of potential CVF biomarkers for IAI. Haptoglobin, unregulated control marker. IGFBP-1 bands represent the intact protein $(\sim 30 \mathrm{kDa})$ and proteolytic fragment $(\sim 19$ $\mathrm{kDa})$. 


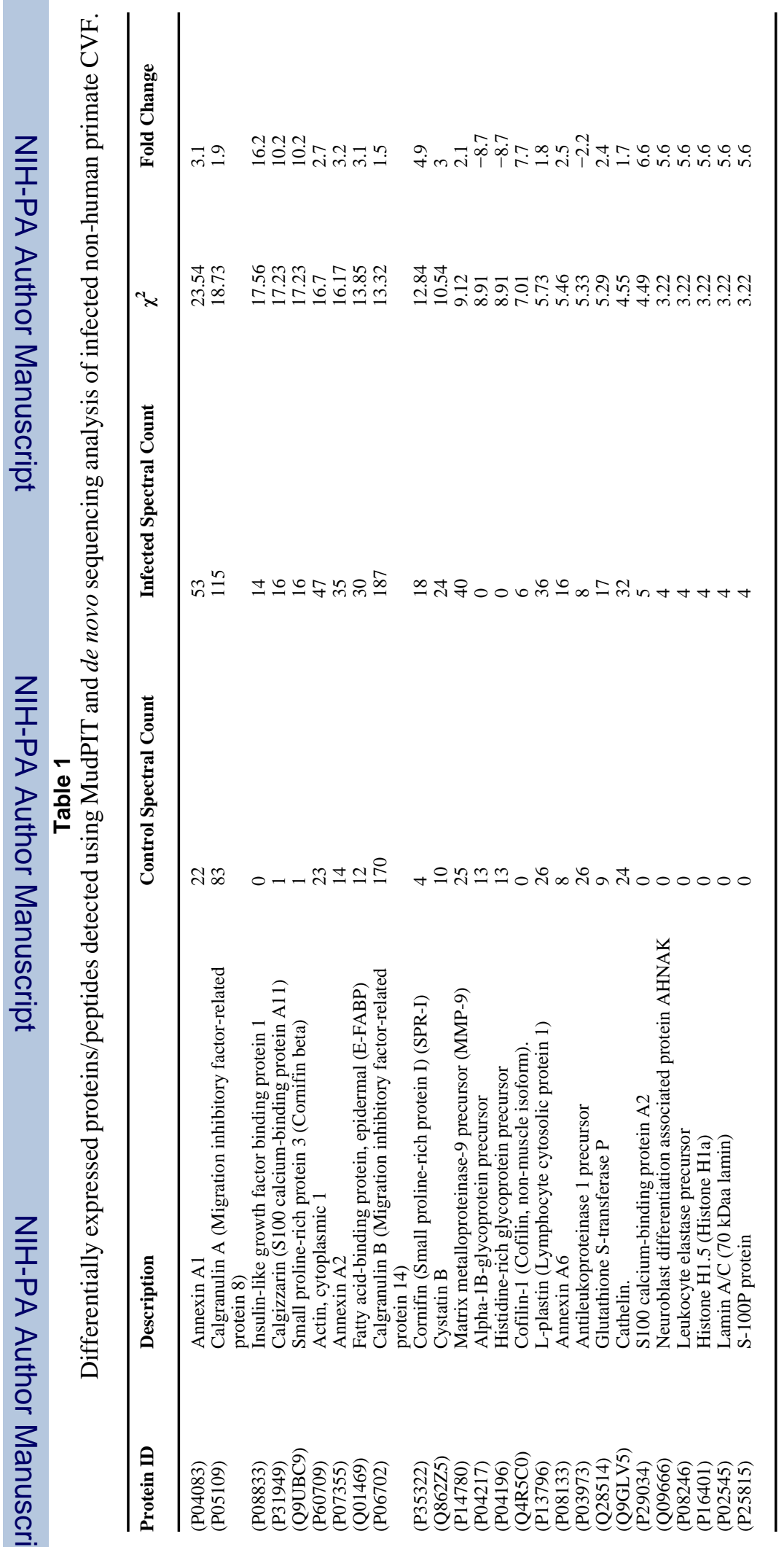

J Proteome Res. Author manuscript; available in PMC 2008 September 9. 